\title{
REFRACTIVE CORRECTION IN A SELECTED ADULT POPULATION IN ISIALA NGWA
}

\author{
BY \\ ALOZIE, I. U. \\ DEPARTMENT OF OPHTHALMOLOGY, \\ NNAMDI AZIKIWE UNIVERSITY TEACHING HOSPITAL, \\ NNEWI, ANAMBRA STATE, NIGERIA. \\ E-mail: ijayalozie@yahoo.com
}

\begin{abstract}
7 his study was carried out to determine the types, distribution and frequency of refractive errors in adults in Isiala Ngwa South L.G.A. A 3-day vision screening program was carried out in 1 November 2007 in which three hundred and forty two adults aged 40 to 80 years were screened for

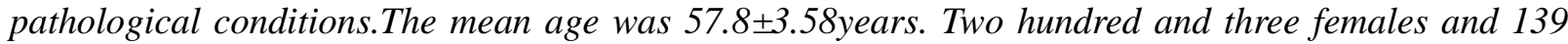
males were screened and refracted. Prevalence of myopia, hyperopia and astigmatism found were $7.20 \%$, $80.30 \%$ and $3.50 \%$ respectively. Emmetropes were found to be $9.07 \%$. The most prevalent refractive error was hyperopia (80.30\%). The occupations of the population screened were found to be mainly farming (47.95\%), followed by civil service (15.20\%) and trading (11.98\%). The most prevalent age group in the population was 51-55years (26\%).
\end{abstract}

KEYWORDS: Vision screening, myopia, hyperopia, astigmatism, presbyopia, community eye health.

\section{INTRODUCTION}

Refractive error has been recognized as a cause of blindness subsequently correction of uncorrected refractive error was included as a component of the global initiative of Vision $2020^{1}$. There are 314 million people, who are visually impaired worldwide ( 45 million who are blind and a further 269 million with visual impairment $)^{2}$. In many developing countries up to $80 \%$ of these blindness is avoidable; 35 million persons require low vision service, and an estimated $50 \%$ of these with impaired vision could be cured with the use of spectacles ${ }^{3}$.

Little is truly known about the actual cause of ametropia, many suggestions have been given; one of such suggestions is the biological view which states that a moderate amount of ametropia is a normal variant caused by environment and genetic factors in man and environmental factors have been reported to influence the development of refractive errors. Incidence and prevalence of most eye diseases are influenced by environment and it varies from place to place and also depends on the age group, they also vary with medical and surgical anomalies and population group studied ${ }^{4}$.

Presbyopia or 'old age sight' when it occurs gradually increases over a period of 10 to 12 years and then stabilizes ${ }^{5}$, but presbyopia is not a refractive error. It is now understood that the lens surfaces actually steepens with age and that the hyperopic shift or the lack of myopic shift is due to a decrease in the gradient index of the lens ${ }^{6}$. Grosvenor and Skeates reported on a retrospective longitudinal study of changes in refraction after age 40 that whereas the hyperopic shift was due to the gradually decreasing gradient index of the lens, the shift towards myopia was due to continued axial elongation. Papers published on uncorrected presbyopia in Africa ${ }^{8}$ and Asia ${ }^{9}$ show that in some countries up to $94 \%$ of the people with presbyopia have no vision correction at all. Those who cannot access an eye examination and receive spectacle may therefore number well over 500 million people $^{10}$.

Isieketa community was randomly selected from the eighteen communities that make up Isiala Ngwa South L.G.A. The dwellers are mainly farmers that produce cassava and vegetables. There is an existing health centre in Isieketa. The nearest general hospital is at Okpuala Ngwa in Isiala Ngwa North L.G.A. All the eye care professionals live in the cities. Most eye surgeries are carried out at Umuguma Owerri, Imo state or Calabar General Hospital, Cross River State.

This study would help to eliminate avoidable blindness due to refractive error in Isiala Ngwa South and also help in ascertaining the visual need of the populace and establish facilities to help overcome the major eye problem prevalent in the area.

\section{RESEARCH METHODOLOGY}

It was a cross sectional study. A 3-day community eye health program was organized in which 342 adults aged 40 to 80 years were screened for pathological conditions and refracted. The eight villages in Isieketa were numbered one to eight; three villages were randomly selected for the screening.

Advocacy visit to the local government chairman and councilors, traditional ruler, traditional prime minister, village heads, chiefs, religious heads were made six months before the program, and several meetings were held prior to 
the commencement of the program. There were advertisements for free eye examinations and free distribution of eye glasses in churches, village meetings, town union meetings. Three hundred and forty two adults were selected and refracted at the Isieketa Health centre. Four optometrists, two registered nurses, three CHEWS and five teachers participated in the screening.

Case history, external examination, visual acuity (VA), retinoscopy and subjective refraction were performed with Snellen's, E- Charts for all the subjects at 6metres. Near chart in Igbo language, retinoscope, trial lens box and accessories and pen torch were used. Visual acuity of 6/6 at 6metres and $\mathrm{N} 8$ at $40 \mathrm{~cm}^{11}$ were accepted and used as standard as this is the type size for newsprint in the country.

Demographic information on age, sex and occupation were also documented and the findings were analyzed to find the pattern of refractive errors in adults in the community.

\section{RESULTS}

The prevalence of hyperopia was highest $(80.12 \%)$ followed by myopia $(7.33 \%)$ and then astigmatism (3.5\%). 9.07\% were without refractive error (emmetropia; see table 1). The population studied was adult population and were all presbyopes, which shows that the age of onset of presbyopia in Isiala Ngwa South L.G.A is before the age of 40 years.

Table 2 shows the age distribution of the subjects, 51-55 years had the highest prevalence of hyperopia. There were more females than males in the ratio of $2: 1 ; 66 \%$ females and $34 \%$ males. The prevalence and degree of hyperopia was highest in females. The prominent occupation of the subjects was farming. Table 3 shows the occupations of the subjects. Farmers topped the list with a prevalence of $47.95 \%$, followed by civil servants $(15.20 \%)$ and traders $(11.80 \%)$. Artisans and tailors were the least with prevalence of $6.40 \%$ and $2.34 \%$ respectively. There were other pathological eye diseases like cataract, glaucoma, retinal degeneration and others but the study was basically to know the prevalence of refractive error in the community, hence, they were not documented.

\section{DISCUSSION}

The result obtained in this study showed that all the subjects were presbyopes. Prevalence of hyperopia was found to be highest; this conforms to studies by Nworah and Ezepue ${ }^{12}$ who documented hyperopia as the commonest error in Enugu. Amos ${ }^{13}$ also reported a higher prevalence of hyperopia than myopia in rural area with poorly schooled populations as opposed to urban areas.

Women had more prevalence of refractive errors than men; studies by Burk et al ${ }^{14}$ also recorded higher prevalence in females than in males in Tanzania. Study by Morny ${ }^{15}$ in Ghana indicated higher prevalence of hyperopia in adult women.

The majority of people in this study do not know where to get spectacles. Among those who knew where to go, $50 \%$ were misinformed about where they were available and half could not afford to travel to a location where help could be obtained. Therefore, it is very difficult to obtain spectacles for persons in the rural villages of Isieketa community. The health personnel at the Isieketa Health Centre were trained in identification and proper referrals of eye problems.

Refractive error affects the quality of life, it is a misconception that refractive error and presbyopia have no impact on quality of life in population where reading and writing are less part of daily life, because vision is also needed for weeding, sowing, cooking, sorting rice, sorting palm fruit etc.

In general, lack of knowledge about refractive services, poor accessibility and additional cost of transportation are challenges for refractive error services intervention program in this area. Rural awareness programs need to be promoted and establishment of eye care services in the existing Isieketa Health Centre and the training of the CHEWS in the Health Centre are recommended. There is need for the establishment of an Eye care unit and employment of optometrist in the Okpuala Ngwa General Hospital.

\section{REFERENCES}

1. Donders, L. (2001): Blindness in the Indian state of Andra Pradesh. Invest Ophthalmol. Vis. Sci, 42(5): 908-16.

2. Foster, A. (2008): Changing patterns in Global Blindness 1988-2008. J. Comm Eye Hlth. In press.

3. Holden, B. A. and Resnikaff. (2002): The role of Optometry in Vision 2020. J. Comm. Eye Hlth, 5(43): 6-9.

4. Parsinnet, T.O. (1987): Relation between refraction, education, occupation and age among 26 and 40yrs old Finns. Am. J. Optom. Phys. Optics, 46(2): 36-143.

5. Grosvenor, T. (2007): Primary Care Optometry. $5^{\text {th }}$ Edn. Butterworth-Heinemann, pp404-15.

6. Pierscionek, B. K. (1993): What we know and understand about presbyopia. Clin. Exp. Optom, 79: 83-90.

7. Grosvenor, T. and Skeates, P. D. (1999): Is 
there a hyperopic shift in myopic eyes during the presbyopic years? Clin. Exp. Optom, 82: 236-43.

8. Patel, I. (1997): Impact of presbyopia on quality of life in a rural African setting. Ophthalmol, 113(5): 728-34.

9. Bourne R. R. (2005): The Pakistan national blindness and visual impairment survey: research design, eye examination methodology and results of the pilot study. Ophthalmol. Epidemol, 12 (5): 321-33.

10. Holden, B. A. (2007): Uncorrected Refractive error: the major and the most easily avoidable cause of vision loss. J. Comm. Eye Hlth, 20(63): 37-9.

11. Patel, I. and West, S. K. (2007): Presbyopia: Prevalence impact and interventions. J.
Comm. Eye Hlth, 20: 40-1.

12. Nworah, P. B. and Ezepue, V. F. (1992): Prevalence of errors of refraction in a Nigerian eye clinic. Orient J. Med, 4: 57-60.

13. Amos, J. F. (1987): Diagnosis and management in vision care. ButterworthHeinemann Ltd, pp101-61.

14. Burke, A. G., Patel, I., Munoz, B., Kayongoya, A., McHiwa, W., Schwarzwalder, A. W. and West S. K. (2006): Prevalence of presbyopia in rural Tanzania: a population based study. Ophthalmol, 113:723-7.

15. Morny, F. K. (1995); Correlation between presbyopa, age and number of births of mothers in the Kumasi area of Ghana. Ophthalmol. Physol. Optom, 15:463-6.

TABLE 1: PREVALENCE OF REFRACTIVE ERRORS

\begin{tabular}{|l|l|l|}
\hline Refractive error & Frequency & \% Frequency \\
\hline Myopia & 25 & 7.31 \\
Hyperopia & 274 & 80.12 \\
Astigmatism & 12 & 3.50 \\
Emmetropia & 31 & 9.07 \\
Total & 342 & 100.00 \\
\hline
\end{tabular}

TABLE 2: AGE DISTRIBUTION OF THE SUBJECTS

\begin{tabular}{|l|l|l|}
\hline Age groups (yrs) & Frequency & \% Frequency \\
\hline $41-45$ & 32 & 10.00 \\
$46-50$ & 65 & 18.00 \\
$51-55$ & 92 & 26.00 \\
$56-60$ & 74 & 22.00 \\
$61-65$ & 30 & 9.00 \\
$66-70$ & 32 & 7.00 \\
$71-75$ & 17 & 5.00 \\
$76-80$ & 10 & 3.00 \\
Total & 342 & 100.00 \\
\hline
\end{tabular}

TABLE 3: OCCUPATION OF THE SUBJECTS

\begin{tabular}{|l|l|l|}
\hline Occupation & Frequency & \% Frequency \\
\hline Civil Servants & 52 & 15.20 \\
Farmers & 164 & 47.95 \\
Tailors & 8 & 2.34 \\
Artisans & 22 & 6.40 \\
Traders & 41 & 11.98 \\
Pensioners & 28 & 8.18 \\
Unemployed & 27 & 7.89 \\
TOTAL & 342 & 100 \\
\hline
\end{tabular}

